\title{
A New Attitudinal Integral-Model to Explain Green Purchase Intention
}

\author{
Francisco Sarabia-Andreu ${ }^{1, * \mathbb{C}}$, Francisco J. Sarabia-Sánchez ${ }^{2} \mathbb{D}$ and Pablo Moreno-Albaladejo ${ }^{3}$ \\ 1 Social and Business Faculty, San Antonio Catholic University, 30107 Murcia, Spain \\ 2 Department of Business and Financial Studies, Miguel Hernandez University, 03202 Elche, Spain; \\ fransarabia@umh.es \\ 3 Department of Marketing and Market Research, University of Murcia, 30100 Murcia, Spain; p.moreno@um.es \\ * Correspondence: fjsarabia@alu.ucam.edu
}

Received: 16 October 2019; Accepted: 6 November 2019; Published: 8 November 2019

check for updates

\begin{abstract}
This study explores the relationship between different implicit and explicit attitudes and green purchase intention. A distinction is made between the cognitive and affective components of implicit attitudes. Negative-oriented attitudes such as cynicism and skepticism are also examined. The data collection process provided 724 responses to two online Implicit Association Tests, followed by a questionnaire on explicit attitudes. Two products (insecticide and toothpaste) in green and conventional formats were used. Each individual responded to a random choice of one of these two products. Structural equation modeling was used to test the research hypotheses. The cognitive and affective components of implicit attitudes were confirmed to be different constructs. Only the cognitive construct was observed to influence attitudes toward green products. Skepticism was observed to negatively influence attitudes toward green products, although it was not found to influence either attitudes toward purchasing green products versus conventional products or purchase intentions. This study offers an innovative approach by examining different types of attitudes that have never been analyzed together in the literature on green products.
\end{abstract}

Keywords: implicit attitudes; explicit attitudes; cognitive attitudes; green products; skepticism; cynicism; purchase intention

\section{Introduction}

Green products, which are also described as "sustainable," "environmentally friendly," "pro-environmental," and a host of other terms, have undergone considerable development in the last two decades. This development owes to an increase in consumer environmental awareness [1] and initiatives by industry and institutions [2,3]. However, it is still common to encounter contradictory behaviors in relation to the environment. For example, plastic bags are eschewed, while harmful pesticides and cleaning products are profusely used. Similarly, the separation of waste in the home has increased, yet products that are difficult to recycle are still popular.

The literature shows that attitudes, knowledge, values, environmental awareness, and perceived effectiveness are antecedents of green purchase intention [4-6]. However, in the case of attitudes, the literature scarcely addresses the role of implicit attitudes and negative-oriented attitudes in the development of green purchase intention. Although implicit attitudes affect almost all human behaviors [7], only a few studies have analyzed their influence on green purchase choice and behavior [8-10]. There is a rich literature on the role of cynicism and skepticism (as negative-oriented attitudes) in green purchase behavior [11,12], specifically in relation to green purchase intention [13-15].

Implicit attitudes are important because, unlike declared or conscious attitudes, they improve the prediction of behaviors that require little cognitive processing and are more spontaneous $[16,17]$. 
Likewise, cynicism and skepticism are relevant attitudes because they negatively influence purchase intentions $[13,14]$ as a result of questioning the safety, functionality, and veracity of the claims made about green products. In short, there is a need to understand what types of attitudes shape green purchase intention. In contrast, seemingly no studies offer comprehensive analysis of all of these types of attitudes. This study fills this gap in the literature.

\section{State of the Art}

\subsection{Green Purchase Intention}

Purchase intention can be understood as the willingness to acquire a product in the future. Most of the literature presents purchase intention as a conscious plan to perform a future behavior (e.g., [18]), expressed as a subjective probability of what the consumer wishes to achieve [19]. Purchase intention has also been considered the result of a comparison between the attitudes, advantages, and perceived drawbacks of a product [20]. Kim and Ko [21] stressed its attitudinal nature, which combines consumers' interest in and predisposition toward making a future purchase, describing purchase intention as a measure of a consumer's future contribution to a product or brand. The intention to purchase also refers to the willingness to express emotions. Emotions play a key role in the desires of consumers and, therefore, in their predisposition to purchase [22]. Thus, although the rationalist approach is part of the equation to explain the human behavior, the predominance of rational mechanisms is surpassed. There is wide consensus that emotions are what really govern human behavior [23]. Also, in the field of marketing, we have moved from an approach based on supply and the rational study of the consumer to a marketing based on experiences and emotions [24].

Purchase intention has proven to be a good general predictor of future behavior, with greater predictive capacity in the short term and under conditions that tend to be easily met [25]. Therefore, it has been used as the best proxy of future behavior both to predict the sales of existing products and to estimate the potential demand of new products [26]. In practice, purchase intention is a consumer's declaration of a predisposition to purchase, barring any significant contingencies in the market or the consumer's personal situation.

\subsection{Attitudes as Antecedents of Green Purchase Intention}

\subsubsection{An Overview of Attitudes}

All relevant explanatory models of purchase intention depict attitudes as an important antecedent [19,27]. Many approaches have been proposed to define and understand attitudes [28]. The most widespread conception is to consider them as a multifaceted phenomenon that expresses a tendency to act in a certain way. This tendency is derived from the overall evaluation of ideas, objects, or people and has three fundamental characteristics: Stability (unlike motivations, which are more short term), a relationship between the person and the object, and polarity (the person takes a favorable, unfavorable, or ambivalent stance toward the object [29]).

Attitudes are temporal constructions that stem from general evaluations based on cognitions and previous evaluations, although they are not stored in the minds of consumers [30]. Accordingly, the intensity and valence of an attitude are strongly associated with the idea that consumers have of the product at the time they make an evaluation. Because this evaluation is irreversible, it decays over time [28]. However, the literature also shows that there are highly persistent attitudes, including negative attitudes such as contempt and cynicism [31,32] and implicit attitudes that are rooted in early-life experiences [33].

Scholars have established the existence of a dual-attitude structure $[34,35]$ that differentiates between implicit, or unconscious, attitudes and explicit, or conscious, attitudes. Whereas implicit attitudes are highly stable and resistant to change, explicit attitudes are more malleable and can change quickly $[34,36]$. Although it has been shown that the two types of attitudes might be different 
manifestations of the same mental structure [37], low correlations between their measurements in a wide range of areas have been reported [38], and there is a long-established literature discussing their differences $[38,39]$.

\subsubsection{Implicit Attitudes}

The general assumption is that implicit attitudes are "traces of past experience that mediate favorable or unfavorable feeling, thought or action" [40] with four fundamental characteristics: Unconscious intent, efficiency, lack of awareness, and lack of control [41]. Today, implicit attitudes are considered to form a fundamental part of the drivers of behavior and to be present in many kinds of behaviors, from behaviors related to health, product consumption, and news media to spontaneous affect in daily life $[7,42]$.

As occurs with explicit attitudes, the cognitive and affective dimensions are essential to implicit attitudes [43,44]. These two dimensions reflect the inputs and mental processes related to stereotypes and prejudices. The affective dimension refers to implicit social archetypes, whereas the cognitive dimension refers to prejudices, since they stem from concepts and beliefs [45]. Similarly, recent advances in neuroscience [46] have shown that the models of automatic association (affective) and deliberation (cognitive) are useful to explain how implicit attitudes act. Moreover, Trendel and Werle [47] found that both attitudinal dimensions are constructed independently of overall implicit attitude. The following hypothesis is thus proposed:

Hypothesis 1 (H1). The cognitive and affective dimensions of implicit attitudes are separate constructs.

In relation to "green products," Vantomme et al. [8] reported that implicit and explicit attitudes may be dissociated, although they observed inconsistent results in terms of their role. Whereas one experiment showed that implicit attitudes toward green products are more positive than toward conventional products, another experiment did not show this difference. Regarding environmental attitudes, Levine and Strube [9] found that implicit and explicit attitudes are significantly related to one another. Along these lines, Pegan and Luca [10] found that the two types of attitudes are positively and significantly correlated. Because implicit attitudes may have separate affective and cognitive dimensions and certain findings indicate an inconsistent influence of implicit attitudes on explicit attitudes, the following hypotheses are proposed:

Hypothesis 2 (H2). The cognitive dimension of implicit attitudes influences explicit (conscious) attitudes toward green products.

Hypothesis 3 (H3). The affective dimension of implicit attitudes influences explicit (conscious) attitudes toward green products.

\subsubsection{Consumer Cynicism and Skepticism}

Attitudes refer to the evaluation of a phenomenon of a neutral or ambivalent nature (the perception of green products need not be good or bad per se). However, certain attitudes have a negative-oriented nature, referring to resistance, opposition, hostility, confusion, or mistrust regarding the true nature, attributes, and functionality of green products and the purchase of these products [1,31]. These attitudes are especially important because they are difficult to change and because they are a fundamental part of the comparative evaluations that consumers make in their decision processes. In practice, they can nullify purchase intention [48].

Cynicism is a multifaceted, complex phenomenon that manifests itself in a wide variety of areas of human activity, appearing in the form of political, psychological, societal, organizational, and consumer cynicism. Cynicism can be understood as a philosophy of life, a feeling, a stable dimension of human personality, or a manifestation of mistrust toward the motivations and actions of others [49]. Many 
theories (e.g., social exchange theory, psychological contract theory, and frustration-aggression theory) support the idea that cynicism is an inextricable element of human behavior [50], with an extensive literature discussing its antecedents and consequences [51,52].

Cynicism is typically defined as a negative, stable, and learned attitude that consumers hold against markets, firms, or products because they perceive a widespread opportunism of firms that is to their detriment $[53,54]$. For most scholars, cynicism is a response based on a general mistrust that manifests itself in not believing in the goodness of human motives and actions. For example, based on Pollay's research [55], Odou and De Pechpeyrou [56] defined cynicism as a constant state of suspicion, used as a psychological weapon to neutralize the influence of marketing actions.

Unlike cynicism, skepticism may be considered a situational doubt, suspicion, or disbelief. It causes consumers to be averse to something in particular and is a primarily cognitive response to communication (advertising, claims made on packaging, etc.) that is influenced by context [57]. Although these concepts are closely linked and have been used indistinctly [11], there is empirical evidence that they are different constructs [48]. For example, Ryu and Jun [58] showed that skeptics doubt the facts and tend to seek information to discern the truth, whereas cynics not only fail to believe the facts but also tend to infer selfish hidden motives. Furthermore, Goh and Balaji [12] do not view skepticism as a stable long-term attitude but rather as a consumer response that may vary according to the context or situation.

Helm et al. [54] showed that both attitudes have a subtle yet widespread effect on consumer behavior. Accordingly, it is reasonable to deduce that this effect also occurs with green products and that the relationship between cynicism and skepticism is direct and positive. Therefore, the following hypothesis is proposed:

Hypothesis 4 (H4). In reference to green products, cynicism is positively related to skepticism.

The literature stresses the idea that skepticism has a significant impact on consumer attitudes and behaviors [15,59]. It has been shown that green consumers are especially skeptical with respect to advertising and claims, demanding extra information on green products as a strategy to alleviate their doubts [11]. Goh and Balaji [12] also report that the most skeptical consumers tend to have more negative attitudes toward the purchase of these products. Therefore, the following hypotheses are proposed:

Hypothesis 5 (H5). Skepticism is negatively related to attitudes toward green products.

Hypothesis 6 (H6). Skepticism is negatively related to attitudes toward the purchase of green products.

Hypothesis 7 (H7). Skepticism is negatively related to green purchase intention.

\subsubsection{Explicit Attitudes toward Green Products and the Purchase of Green Products}

The generation of attitudes toward green products and the predisposition to purchase these products are two distinct phenomena. Attitudes toward green products derive from a generic comparison of the superior qualities of these products without considering them a potential choice by the consumer. Nevertheless, the predisposition to purchase green products also entails emotional and functional antecedents $[60,61]$ that affect a choice that is prior to purchasing, whereby the possibility of purchasing a green product is compared with that of purchasing another product that is not green.

Attitudes toward green products are known to be higher than attitudes toward conventional products [62], as is also the case in other positive-natured areas such as health, exercise, and food safety. However, there is also a gap between attitudes (toward a product) and their manifestation in the form of attitudes toward a purchase. Given that attitudes toward a product influence attitudes toward purchasing that product $[63,64]$, the following hypothesis is proposed: 
Hypothesis 8 (H8). Attitudes toward green products influence attitudes toward the purchase of these products.

The literature shows that, in general, attitudes are a solid antecedent of purchase intention. In reference to green products, Honkanen et al. [65] and Demirtas [66], among others, have shown a significant positive relationship between attitudes toward green products and the intention to purchase these products. Nevertheless, for certain aspects that are strongly related to attitudes, different relationships have been found. For example, D'Souza et al. [67] found a negative relationship between the general view of green products and purchase intention, and Wee et al. [68] did not find a significant effect of this perception on intentions to purchase organic food. Therefore, the following hypothesis is proposed:

Hypothesis 9 (H9). Attitudes toward the purchase of green products influence future purchase intentions.

The proposed empirical model appears in Figure 1.

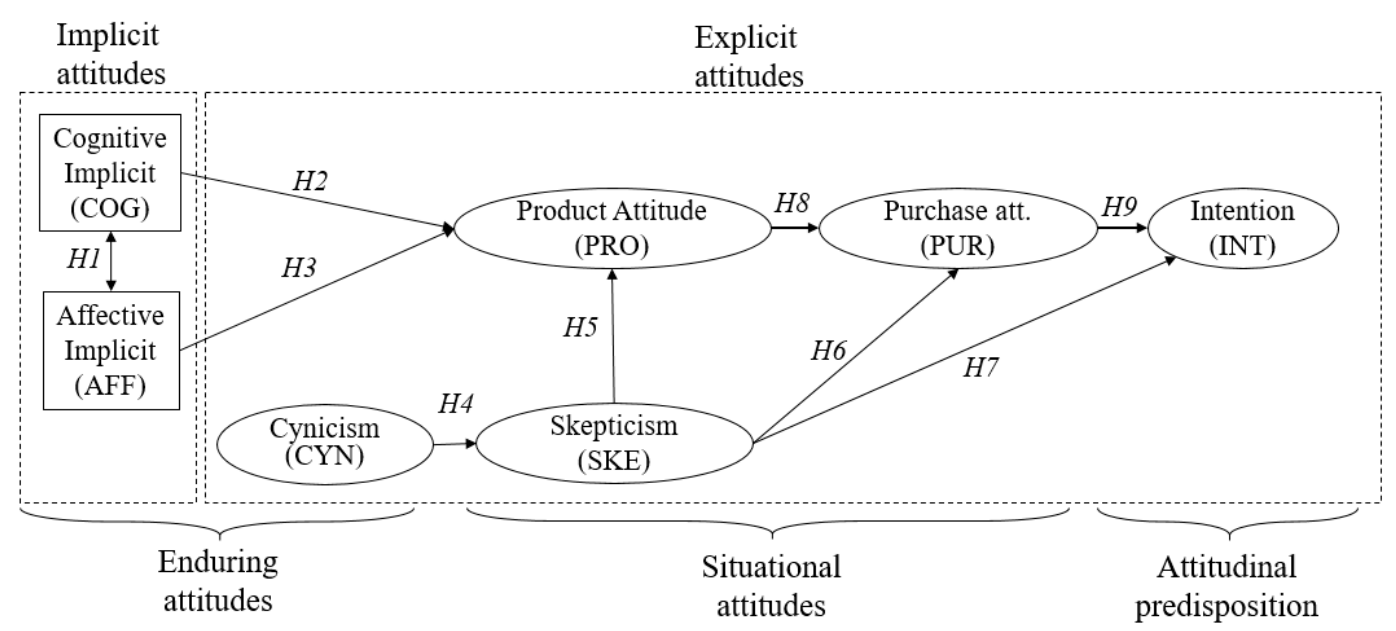

Figure 1. Proposed attitudinal model.

\section{Method and Materials}

\subsection{Fieldwork and Participants}

\subsubsection{Fieldwork}

Data were collected in May 2018 by recruiters who contacted participants to respond to an online questionnaire. There were five requirements to be invited to participate: (1) to be aged from 25 to 65 years, (2) to have a home Internet connection, (3) to be a Spanish resident and have a native level of the Spanish language (the questionnaire was in Spanish), (4) to have no mobility issues with hands or arms and have no disability that prevented the use of a computer keyboard and mouse to complete the online questionnaire, and (5) to be willing to collaborate in a scientific study. The recruiters explained that the questionnaire should be completed when the respondents had 15 minutes of time available at home rather than at work or while traveling to avoid distractions and that the respondents should complete the questionnaire alone from a desktop or laptop computer.

The participants were contacted personally by recruiters using systematic sampling in public places and on social media. The places to recruit participants were bus and train stations, and shopping malls. Each recruiter contacted every 10 minutes with those who passed by him/her (e.g., 18:00 h, 18:10, 18:20, 18:30). For social networks, each recruiter used the following system: (1) Visit profiles on Facebook, Instagram, Twitter, or LinkedIn (profiles contacted must alternate gender and age level); (2) request participation in the study by sending a private presentation message; and (3) after receiving each positive response, the web link was sent. Each recruiter verified that his/her sampling quotas 
were fulfilled (Male $=$ Female $=50 \%$; Boomers $=$ Generation $X=$ Millennial $=33 \%$ ), and each new participant resided in a different municipality. Likewise, each recruiter could choose the place and/or the social network. The people contacted received a message or physical card with the basic description of the study and the web link to access the online questionnaire.

The participants were informed that there would be no financial reward, that their participation would enable "research into an important complex phenomenon in green purchasing," (Different names were analyzed for the product categories: (Green; Environmental; Organic; Natural; Environmentally friendly; Sustainable) vs. (Non-green; Non-environmental; Non-organic; Chemical; Conventional; Non-sustainable)). In the Spanish questionnaire, these terms appeared as (Ecológico; Ambiental; Orgánico; Natural; Respetuoso con el entorno; Sostenible) vs. (No ecológico; No ambiental; No orgánico; Químico; Convencional; No sostenible). In Spain, the term "organic" ("orgánico") is hardly used by consumers. In this study, we used the term "green" ("ecológico") because it is more identifiable and commonly used. The respondents also were told the questionnaire do not collect any personally identifiable information.

\subsubsection{Participants}

In total, 841 consumers were contacted, and 724 valid responses were gathered (86.2\%) from consumers in 62 cities in Spain. The sample is made up of a $50.3 \%$ of women, with age mean of $41.7(\mathrm{SD}=11.6)$. By generation, the consumers belonged to the Baby Boomers $(32.2 \%), X(29.7 \%)$, and Millennial (38.1\%) generations. Regarding education, $4.6 \%$ had primary education, $12.2 \%$ lower secondary, $29.3 \%$ upper secondary, $12.6 \%$ undergraduate, and $41.4 \%$ postgraduate.

\subsection{Instruments (Items of the Different Instruments are Detailed in the Results Section)}

\subsubsection{Green Purchase Intention (INT)}

Lee's proposal [69] to measure "green purchase intention" was adopted. This proposal is based on studies by Kim and Pysarchik [70] and Chan [71]. The instrument is a four-item, 7-point Likert-type scale ranging from 1 (strongly disagree) to 7 (strongly agree). The item "I feel like buying a pro-environmental product [toothpaste/insecticide]" was discarded because during the pretest participants did not understand the concept of "I feel like buying ... " to evaluate products that are considered utilitarian. Instead, the item "Next time, I will show an interest in buying a green [toothpaste/insecticide]" was included.

\subsubsection{Implicit Attitudes (COG; AFF)}

The Implicit Association Test (IAT), which was developed by Greenwald et al. [72], was used. This test is valid for the measurement of individuals' implicit attitudes [73] and is widely used in the literature [74]. The IAT measures the intensity of the automatic associations between certain concepts. It is a measure of an individual's underlying predisposition toward an object or phenomenon. The IAT uses discrimination concepts, attributes, and stimuli that are combined, using a standard protocol, to produce a measure of the association that each individual makes between concepts and attributes. This test has been used to study implicit attitudes toward genetically modified food [75], the role of implicit attitudes in the choice of organic food [76] and the capacity of implicit attitudes to explain intentions to buy organic wine [77]. The IAT is considered a good predictor of actual behavior.

However, the IAT is unable to distinguish between the dimensions that contribute to general attitudes, offering only a single overall score that prevents discrimination between dimensions. This weakness was highlighted by Schnabel et al. [78], who noted that implicit associations may be subject to semantic interpretations. Therefore, adopting Gattol's et al. approach [79] to multidimensional IAT, this study differentiated between implicit attitudes where the emotional dimension is predominant (feelings) and implicit attitudes derived from cognitive processing (thoughts). However, this study did not use the D measure proposed by Gattol et al. [79] but rather the improved algorithm developed 
by Greenwald et al. [80], using the script for R software [81]. Thus, two linked IATs were proposed: An initial IAT where the stimuli were only cognitive and a subsequent IAT where the stimuli were exclusively affective. Section 3.3 details the procedure used to build these two IATs.

The intensity of the association was calculated using the average time taken by the individuals to assign responses to the stimuli. This calculation provided a score that resembles the concept of effect size. This score is dimensionless and ranges from -2 to +2 . To interpret this score, the same breakpoints as for Cohen's d statistic are usually used, namely $0.20=$ small, $0.50=$ medium, $0.80=$ large, and $1.30=$ very large [82]. The sign of the score indicates the type of association. Thus, a positive sign would imply that the concept "green" is associated with the positive attributes and that the concept of "non-green" is associated with the negative attributes. A negative sign would mean the opposite.

\subsubsection{Explicit Attitudes toward Green Products (PRO)}

Gil et al.'s [83] nine-item, 7-point Likert scale ranging from 1 (strongly disagree) to 7 (strongly agree) was used. This instrument was developed to measure individuals' predisposition toward organic food, but it can be used for any other type of product. The respondents were asked to "indicate your degree of agreement or disagreement with the following statements." Gil et al. [83] detected two factors (positive and negative aspects), and the scale has been used in previous studies, offering high levels of reliability (Cronbach's alpha $>0.8$ ) and sufficient validity [84]. The original wording of the items was preserved, except that "Organic products" was changed to "Los productos ecológicos."

\subsubsection{Explicit Attitudes toward Purchasing Green Versus Conventional Products (PUR)}

An instrument consisting of items from the scales developed by Berndsen and Van der Pligt [60] and Thøgersen et al. [61] was used. The respondents were asked, "What is it like for you to buy green products instead of conventional products?" An eight 7-point semantic differential items were used. Each item was identified with a pair of opposite states: Harmful-Beneficial, Foolish-Wise, Good-Bad (reversed), Unpleasant-Pleasant, Against-For, Unfavorable-Favorable and Positive-Negative (reversed). An extra item extra was added with the states Unattractive-Attractive to give a greater balance between items of cognitive and affective natures.

\subsubsection{Consumer Cynicism (CYN)}

The eight-item 7-point Likert scale ranging from 1 (strongly disagree) to 7 (strongly agree) proposed by Helm et al. [54] was used. The reliability reported by these authors was greater than 0.8, and the instrument met the criteria of convergent and discriminant validity. Swalwell [85] reported a reliability of 0.95 and mean inter-item correlation of 0.71 and indicated that the instrument met the validity requirements.

\subsubsection{Consumer Skepticism (SKE)}

The instrument proposed by Mohr et al. [57], which consists of four 7-point Likert-type items ranging from 1 (strongly disagree) to 7 (strongly agree), was used. For the original version, sufficient reliability was reported (0.79), and the instrument met the requirements for convergent and discriminant validity. Recent studies [86] have reported reliabilities of between 0.80 and 0.83 and have indicated that the instrument had convergent and discriminant validity. An additional item was added in the form of the statement, "I sometimes doubt that these messages are true," in reference to environmentally friendly claims.

\subsection{Procedure and Questionnaire}

\subsubsection{Design of the IATs}

The 6-stage procedure followed in this study is now described. 
Stage 1. Establish the dimensions of each IAT. One IAT focused on the cognitive dimension, while the other focused on the affective dimension. For the cognitive dimension, the quality of "functionality" was chosen, whereas for the affective dimension, the quality of "favorability" was chosen. Whereas the first quality refers to rational perceptions, the second refers to feelings.

Stage 2. Establish the basic elements for each IAT. First, target concepts "Organic" vs. "Non-organic." These concepts were represented using images of the products and their packaging, which enabled differentiation between the concepts of "Organic" and "Non-organic." The cognitive and affective IATs presented the same target concepts. Second, discrimination attributes. They were the names used to express the positive and negative aspects of the attributes. For the cognitive IAT, the attributes were "Effective-Ineffective," and for the affective IAT, the attributes were "Favorable-Unfavorable."

Stage 3. Choose the stimuli for each attribute. A list of 15 words was prepared for each attribute. These words were voted on by two groups of university students (mean age of Group 1:22 years; mean age of Group 2:40 years). Each student chose a maximum of three stimuli that best evoked the attributes. Finally, the four words chosen the most for each item were kept.

Stage 4. Choose the products. The products had to have four characteristics:

1. Universal use so that all respondents were familiar with using these products.

2. No sex or age bias. For example, products such as hairspray (mainly for women) or hair gel (mainly for men) had to be avoided, as did products mainly consumed by a certain generation (e.g., wine, which is consumed mainly by older consumers).

3. Packaging that clearly displays differences between organic and non-organic versions.

4. Similar average price so that a large perceived difference in product price does not introduce uncontrolled bias.

Finally, a list of three products (insecticide, toothpaste, and shampoo) was prepared. Insecticide and toothpaste were chosen to prevent both products from belonging to the same product category (personal hygiene).

Stage 5. Choose images to be presented. A search for public images of products was conducted. Three were chosen for each target concept (organic and non-organic) and product. Some brands did not have any organic version, so the organic version was created by modifying the original image (for an example, see Appendix A). To avoid the possible effect of brand reputation, products that were not available in the Spanish market were chosen.

Stage 6. Choose instruments described in Section 4.2.

\subsubsection{Questionnaire}

A three-part online questionnaire was designed. The first part requested informed consent, indicating the scientific nature of the study, the voluntary nature of participation, and the fact that no personally identifiable information would be collected. The second part consisted of the two consecutive IATs. The first IAT comprised the cognitive attributes, while the second consisted of the emotional attributes. The third part included questions related to the variables of green purchase intention (both in general and for specific products), explicit attitudes, skepticism, cynicism, and basic sociodemographic variables (age, sex, and education).

The images did not contain details of textual information, initials, or symbols so that the images were clear, easy to visualize, and uncluttered. It was deemed that cluttered images could slow response times, transforming the responses to non-automatic responses. The IATs used images of packaging with real and dummy brands that were little known or unknown in the Spanish market. All images were public and high quality, and they were gathered from the Internet or created ad hoc.

The questionnaire was pretested with a group of 15 university students (mean age 22 years) and by three non-university participants aged over 50 years. Formal aspects (wording and layout), structural aspects (response time and dynamics), and content aspects (understanding) were assessed. Table 1 
shows the sequence of tasks completed in the two IATs. Appendix A shows other relevant aspects of both IATs.

Table 1. Sequence of Implicit Association Test (IAT) tasks (for both IATs).

\begin{tabular}{|c|c|c|c|c|}
\hline \multirow{2}{*}{$\begin{array}{c}\text { Round } \\
1\end{array}$} & \multirow{2}{*}{\begin{tabular}{c|} 
Task \\
Target concept discrimination
\end{tabular}} & \multirow{2}{*}{$\begin{array}{l}\text { IAT } \\
\text { Both }\end{array}$} & \multicolumn{2}{|c|}{ Assigned Answers } \\
\hline & & & Green & NGreen \\
\hline & & IAT1 & Func & NFunc \\
\hline 2 & Discrimination of attributes & IAT2 & Favor & Unfavor \\
\hline 3 & Trial of combined tasks & IAT1 & Green and Func & NGreen and NFunc \\
\hline 4 & Test of combined tasks & IAT2 & Green and Favor & NGreen and Unfavor \\
\hline 5 & Reversed target discrimination & Both & NGreen & Green \\
\hline 6 & Trial of reversed combined tasks & IAT1 & NGreen and Func & Green and NFunc \\
\hline 7 & Test of reversed combined tasks & IAT2 & NGreen and Favor & Green and Unfavor \\
\hline
\end{tabular}

Notes: NGreen = Non-green or conventional product, Func $=$ Functional, NFunc $=$ Non-functional, Favor $=$ Positive or favorable emotions, Unfavor $=$ Negative or unfavorable emotions, IAT1 = IAT of cognitive attributes (efficacy), IAT2 $=$ IAT of affective attributes.

\subsection{Methods}

Back-translation was used to translate the items from instruments originally written in English but not adapted to Spanish $[87,88]$. The responses to online information were captured using the software developed by Mason, Allon, and Ozturk [89]. This software provides the degree of association using the speed with which the individuals respond to the presence of the stimuli (images and attributes/words).

All variables included in the model, except implicit attitudes, were calculated using the mean value of the items, subsequently normalized to the range $(0,1)$ to enable better interpretation of the data. EQS Version 6.1 was used to perform the confirmatory factor analysis and the structural equation modeling (SEM), and SPSS V22 was used for all other analyses.

\section{Results}

First, the measurement model was validated using covariance-based confirmatory factor analysis (CFA) with maximum likelihood estimation. Next, the hypotheses were tested using SEM.

\subsection{Validation of the Measurement Model}

To confirm that the explicit attitudinal measures were suitable, CFA was conducted to check the fit of the data matrix to the structure of the proposed constructs, excluding the implicit attitudes because the $\mathrm{D}$ scores were calculated following the procedure described in Section 4.2. It was observed that Mardia's coefficient was 248.51. This value indicated the absence of multivariate normality and required the use of the robust estimation method. The fit was poor, as reflected by the following values: Satorra-Bentler chi-square $(\mathrm{SBCS})=1782.9(\mathrm{df}=584, p<0.05)$, normed chi-square $(\mathrm{NCS})=3.05$, Bentler-Bonett non-normed fit index $(\mathrm{BBNNFI})=0.88$, comparative fit index $(\mathrm{CFI})=0.89$, and root mean square error of approximation (RMSEA) $=0.05$ (RMSEA 90\% CI $=0.05,0.06$ ). Although the values of the CFI and RMSEA were acceptable, the fit indices were below the values recommended in the literature, and the convergent validity of some instruments was not acceptable.

After eliminating items with low factor loadings $(\lambda<0.70)$ an acceptable solution is found: Mardia's coefficient $=140.62, \mathrm{SBCS}=680.39(\mathrm{df}=241, p<0.01), \mathrm{NCS}=2.82, \mathrm{BBNNFI}=0.94, \mathrm{CFI}=0.95$, and RMSEA $=0.05$ (RMSEA 90\% CI $=0.05,0.05$ ). All instruments had sufficient reliability (composite reliability $C R \geq 0.78$ ) and met the conditions of convergent and discriminant validity (see Tables 2 and 3$)$. Convergent validity was verified by using the confirmatory factor loadings $(\lambda>0.70)$ and by checking that the fit indices were greater than 0.90 [90] and that the RMSEA was lower than 0.08. Discriminant validity was verified by using the average variance extracted (AVE) coefficients [91] and by inspecting the confidence intervals of the correlations between the instruments. No interval should contain a correlation value of 1 [92,93]. In this study, all AVE values were greater than 0.50 , and no confidence interval of correlations contained the value 1. 
Table 2. Instruments, items, factor loadings, reliabilities, and convergent validities.

\begin{tabular}{|c|c|c|c|c|c|c|}
\hline Instruments and Items & M (SD) & $\lambda$ & SE & $\mathbf{R}^{2}$ & CR & AVE \\
\hline F1. Purchase intention (INT) & & & & & 0.91 & 0.71 \\
\hline P1. I will definitely consider buying an $X$. & $4.32(1.71)$ & 0.77 & 0.64 & 0.59 & & \\
\hline P2. I will prioritize an $X$ when shopping. & $4.44(1.81)$ & 0.85 & 0.52 & 0.73 & & \\
\hline P3. I will recommend an $X$ to people around me. & $5.00(1.68)$ & 0.86 & 0.50 & 0.75 & & \\
\hline P4. Next time, I will show an interest in buying an $X .\left(^{*}\right)$ & $4.76(1.74)$ & 0.86 & 0.50 & 0.75 & & \\
\hline F2. Attitude toward green products (PRO) & & & & & 0.81 & 0.68 \\
\hline G1. Green products are healthier. & $5.57(1.46)$ & 0.82 & 0.579 & 0.66 & & \\
\hline G2. Green products have superior quality. & $4.99(1.44)$ & 0.83 & 0.555 & 0.69 & & \\
\hline $\begin{array}{l}\text { F3. Attitude toward purchasing green vs. conventional } \\
\text { products (PUR) }\end{array}$ & & & & & 0.93 & 0.66 \\
\hline H1. Harmful—Beneficial. & $5.73(1.15)$ & 0.84 & 0.55 & 0.70 & & \\
\hline H2. Foolish—Wise. & $5.64(1.18)$ & 0.83 & 0.56 & 0.68 & & \\
\hline H3. Good-Bad (Reversed). & $5.84(1.13)$ & 0.78 & 0.63 & 0.61 & & \\
\hline H4. Unpleasant-Pleasant. & $5.38(1.20)$ & 0.82 & 0.58 & 0.67 & & \\
\hline H5. Against-For. & $5.51(1.22)$ & 0.77 & 0.64 & 0.59 & & \\
\hline H6. Unfavorable-Favorable. & $5.66(1.16)$ & 0.87 & 0.50 & 0.75 & & \\
\hline H7. Positive-Negative (Reversed). & $5.86(5.86)$ & 0.77 & 0.64 & 0.59 & & \\
\hline F4. Skepticism (SKE) & & & & & 0.78 & 0.55 \\
\hline $\begin{array}{l}\text { I2. Because environmental claims are exaggerated, } \\
\text { consumers would be better off if such claims on package } \\
\text { labels or in advertising were eliminated. }\end{array}$ & $3.69(1.62)$ & 0.70 & 0.71 & 0.49 & & \\
\hline $\begin{array}{l}\text { I3. Most environmental claims on package labels or in } \\
\text { advertising are intended to mislead rather than to inform } \\
\text { consumers. }\end{array}$ & $4.04(1.68)$ & 0.79 & 0.62 & 0.62 & & \\
\hline I5. Sometimes I doubt that these claims are true. $\left({ }^{*}\right)$ & $4.36(1.74)$ & 0.70 & 0.71 & 0.49 & & \\
\hline F5. Cynicism (CYN) & & & & & 0.91 & 0.62 \\
\hline $\begin{array}{l}\text { K2. Most businesses are more interested in making profits } \\
\text { than in serving consumers. }\end{array}$ & $5.24(1.55)$ & 0.81 & 0.58 & 0.66 & & \\
\hline K3. Companies see consumers as puppets to manipulate. & $5.07(1.62)$ & 0.85 & 0.53 & 0.72 & & \\
\hline $\begin{array}{l}\text { K4. Manufacturers do not care what happens once I have } \\
\text { bought the product. }\end{array}$ & $4.52(1.71)$ & 0.78 & 0.63 & 0.61 & & \\
\hline $\begin{array}{l}\text { K5. If I want to get my money's worth, I cannot believe what } \\
\text { a company tells me. }\end{array}$ & $4.36(1.57)$ & 0.71 & 0.71 & 0.50 & & \\
\hline K6. Most companies will sacrifice anything to make a profit. & $4.72(1.60)$ & 0.80 & 0.61 & 0.63 & & \\
\hline $\begin{array}{l}\text { K7. To make a profit, companies are willing to do whatever } \\
\text { they can get away with. }\end{array}$ & $5.00(1.59)$ & 0.76 & 0.65 & 0.58 & & \\
\hline
\end{tabular}

$\mathrm{X}=$ Green product: insecticide/toothpaste ${ }^{1}, \mathrm{M}=$ mean, $\mathrm{SD}=$ standard deviation, $\lambda=$ standardized factor loading, $\mathrm{SE}=$ standard error, $\mathrm{R}^{2}=\mathrm{R}$-squared, $\mathrm{CR}=$ composite reliability, $\mathrm{AVE}=$ average variance extracted.

Table 3. Discriminant validity of the instruments.

\begin{tabular}{ccccc}
\hline Factors & Cov. & SE & CI of Cov. & CI of Corr. \\
\hline INT-PRO & 0.74 & 0.04 & $0.66,0.81$ & $0.66,0.81$ \\
INT-PUR & 0.45 & 0.03 & $0.39,0.52$ & $0.39,0.52$ \\
INT-SKE & -0.16 & 0.04 & $-0.25,-0.08$ & $-0.25,-0.08$ \\
INT-CYN & -0.02 & 0.04 & $-0.10,0.07$ & $-0.10,0.07$ \\
PRO-PUR & 0.63 & 0.03 & $0.57,0.69$ & $0.57,0.69$ \\
PRO-SKE & -0.30 & 0.04 & $-0.38,-0.22$ & $-0.38,-0.22$ \\
PRO-CYN & -0.07 & 0.04 & $-0.15,0.02$ & $-0.15,0.02$ \\
PUR-SKE & -0.25 & 0.04 & $-0.33,-0.17$ & $-0.33,-0.17$ \\
PUR-CYN & 0.01 & 0.04 & $-0.08,0.08$ & $-0.08,0.08$ \\
SKE-CYN & 0.40 & 0.04 & $0.32,0.47$ & $0.32,0.47$ \\
\hline
\end{tabular}

Cov. = covariance; $\mathrm{CI}=$ confidence interval, Corr. = correlation; $\mathrm{SE}$ = standard error.

\subsection{Hypothesis Testing}

H1 posits that cognitive implicit attitudes and affective implicit attitudes are different constructs. Pearson's correlation test showed that they share a significant association $(\mathrm{r}=0.52, n=724, p<0.05$, Cohen's $d=1.22$ ) but are also different constructs. This is because the confidence interval of the 
correlation did not contain the value $1(95 \% \mathrm{CI}=0.45,0.58$; for 1000 bootstrap samples; $\mathrm{SE}=0.03)$. The effect size was very large.

In relation to attitudes toward green products, a significant positive influence of cognitive implicit attitudes on attitudes toward green products was observed $(\beta=0.28 ; t=2.33 ; p<0.05 ; \mathrm{SE}=0.12)$. Skepticism also negatively influenced attitudes toward green products, as expected $(\beta=-0.31 ; t=5.98$; $p<0.01 ; \mathrm{SE}=0.05)$. Affective implicit attitudes did not influence attitudes toward green products, contrary to what $\mathrm{H} 3$ posits $(\beta=0.04 ; t=0.29 ; p>0.05 ; \mathrm{SE}=0.15)$. Therefore, the results support $\mathrm{H} 2$ and $\mathrm{H} 5$. With respect to the relationship between cynicism and skepticism, a significant positive relationship was observed ( $\beta=0.37 ; t=8.22 ; p<0.01$; SE $=0.04)$, supporting H4. Considering attitudes toward the purchase of green versus conventional products, a positive relationship was observed between attitudes toward green products and attitudes toward the purchase of green versus conventional products, as posited by H8 $(\beta=0.51 ; t=10.57 ; p<0.01 ; \mathrm{SE}=0.05)$. In contrast, such a relationship was not observed for $\mathrm{H} 6$, which posits a relationship between skepticism and attitudes toward the purchase of green versus conventional products, because it cannot be considered different from zero $(\beta=-0.05 ; t=1.39 ; p>0.05 ; \mathrm{SE}=0.03)$. Therefore, the results support H8, but H6 should be rejected.

Finally, with respect to purchase intentions, a significant positive relationship was observed between attitudes toward the purchase of green versus conventional products and purchase intentions, thereby supporting $\mathrm{H} 9(\beta=0.61 ; t=10.29 ; p<0.01 ; \mathrm{SE}=0.06)$. In contrast, the relationship between skepticism and purchase intentions, posited by $\mathrm{H} 7$, was not significant $(\beta=-0.06 ; t=1.21 ; p>0.05$; $\mathrm{SE}=0.05)$. Table 4 summarizes these findings.

Table 4. Hypothesis testing.

\begin{tabular}{|c|c|c|c|c|}
\hline Hypothesis & $\beta$ & Results & $\mathbf{R}^{2}$ & Verified/Not Verified \\
\hline $\mathrm{H} 1[r(\mathrm{COG}, \mathrm{AFF})]$ & $r=0.52$ & $\begin{array}{c}\text { Cohen's d }=1.22 \\
95 \% \text { CI }(0.45,0.58)\end{array}$ & - & Verified \\
\hline $\mathrm{H} 4(\mathrm{CYN} \rightarrow \mathrm{SKE})$ & 0.37 & $\mathrm{t}=8.22 * *$ & 0.15 & Verified \\
\hline $\begin{array}{c}\mathrm{H} 2(\mathrm{COG} \rightarrow \mathrm{PRO}) \\
\mathrm{H} 3(\mathrm{AFF} \rightarrow \mathrm{PRO}) \\
\mathrm{H} 5(\mathrm{SKE} \rightarrow \mathrm{PRO})\end{array}$ & $\begin{array}{c}0.28 \\
0.04 \\
-0.31\end{array}$ & $\begin{array}{c}t=2.33^{*} \\
t=0.29 \text { ns } \\
t=-5.98^{* *}\end{array}$ & 0.10 & $\begin{array}{c}\text { Verified } \\
\text { Not verified } \\
\text { Verified }\end{array}$ \\
\hline $\begin{array}{l}\text { H6 (SKE } \rightarrow \text { PUR) } \\
\text { H6 (SKE } \rightarrow \text { PUR) }\end{array}$ & $\begin{array}{c}-0.05 \\
0.51\end{array}$ & $\begin{array}{l}t=-1.39^{n s} \\
t=10.57^{* *}\end{array}$ & 0.40 & $\begin{array}{l}\text { Not verified } \\
\text { Verified }\end{array}$ \\
\hline $\begin{array}{l}\text { H7 (SKE } \rightarrow \text { INT) } \\
\text { H9 (PUR } \rightarrow \text { INT) }\end{array}$ & $\begin{array}{c}-0.06 \\
0.61\end{array}$ & $\begin{array}{l}t=-1.21^{n s} \\
t=10.29^{* *}\end{array}$ & 0.21 & $\begin{array}{l}\text { Not verified } \\
\text { Verified }\end{array}$ \\
\hline
\end{tabular}

\section{Discussion}

The results support the majority of the hypotheses, reflecting the overall validity of the proposed attitudinal model. First, the results indicate that, as regards implicit attitudes toward green products, the cognitive component can be differentiated from the affective component, which is consistent with the ABC model of attitudes [94] and the findings reported by Trendel and Werle [47]. This finding implies that the preferences or evaluations that are generated outside cognitive processing also have a rational influence from what has been learnt subconsciously and what has been felt unconsciously.

Second, unlike in the study by Trendel and Werle [47], a significant effect was only observed for the effect of cognitive implicit attitudes on explicit attitudes. This finding stands to reason because these authors [47] analyzed responses to the choice of certain foods with a strong hedonic focus (e.g., chocolate). However, the green products considered in this study are functional, so the significance of the cognitive focus makes sense. This outcome is consistent with the findings reported by Maniatis [95], 
according to whom the evaluation of organic aspects requires complex cognitive mental interactions that involve consciousness, knowledge, and commitment.

Third, the results confirm the influence of cynicism on skepticism and of skepticism on attitudes toward green products, which is consistent with the findings reported by Albayrak et al. [14]. This skepticism can act in a positive way (e.g., helping to reduce the impact of a potential disappointment and improving critical thinking) or negatively (e.g., generating tainted evaluations that encourage apathetic or non-environmentally friendly behaviors). Because attitudes toward green products are negatively influenced by skepticism, to improve the attitudes of skeptical consumers, it seems advisable to develop strategies that offer arguments designed to encourage consumers to investigate the advantages of green products. Skeptical individuals are characterized by being highly demanding, not accepting information without first questioning it, and having a certain degree of mistrust as a personality trait. Therefore, to elicit positive attitudes toward green products, it seems advisable to use strategies that encourage a favorable view of green products and underpin their credibility. One strategy that could be used is to increase the reputation via corporate social responsibility and to improve the visibility of green products through institutional campaigns focused on their environmental benefits. In addition, and not least, companies should seek ways to generate economies of scale and reduce the price differential between green and conventional products.

Fourth, purchase attitudes (when green products are compared with conventional products) and purchase intentions are not affected by skepticism. The literature here is ambivalent. For example, Goh and Balaji [12] showed that skepticism reduces purchase intentions (for green products in general), whereas Wei et al. [96] found that it does not influence attitudes or purchase intentions. The results of this study indicate that attitudes and purchase intentions are resistant to a certain degree of consumer prejudice, which is consistent with the findings reported by Wei et al. [96]. This finding could be due to the fact that the formation of attitudes is reinforced by the growing demand for green products in all countries and sectors, and by the consumer's fear of harmful chemicals (for example, pesticides). This may imply the perception that it is good to move away from conventional products, in addition to the fact that greater green awareness protects the willingness to buy.

Fifth and finally, although the explanatory capacity of the model $\left(R^{2}\right)$ is $40 \%$ for attitudes toward purchasing green versus conventional products, $h$ it is lower $\left(R^{2}=20 \%\right)$ for purchase intentions. This difference might mean that attitudes explain a substantial part of the consumer's position when the consumer considers the dilemma of choosing between a green and a conventional product, even though attitudes are incapable of encouraging future purchase decisions with respect to functional products. For consumers, the prospect of functionality is likely to be more relevant for a conventional product than for a green product. Notably, this result is not comparable with other $\mathrm{R}^{2}$ values that have been reported (e.g., for upcycled products, [97]) because the model presented in this paper is solely attitudinal and does not include other perceptual variables. Further research is needed on this crucial point.

The results presented here should be considered in the light of two potential limitations. The first is methodological and is associated with the cognitive and affective IATs, which were presented in the same order to all participants. This procedure might have created an order bias because the software that was used prevented the randomization of the questionnaire blocks. Although there is evidence to suggest that the order in which the IATs are presented does not influence (or has only a minor influence) on the results [98], eliminating this order bias would be advisable in future studies. The second limitation refers to how the sample was drawn. All participants were residents in a country where the green market has grown massively in recent years, placing Spain among the top 10 countries with the highest organic consumption worldwide [99]. The replication of this study in countries with more or less development in the green sector would enable confirmation that the results reported here may be generalized and would allow evaluation of possible moderation by degree of development of the green market. 
Author Contributions: Paper conceptualization, F.S.-A. and F.J.S.-S.; study administration and data collection, all authors; methodology, F.S.-A. and F.J.S.-S.; writing-original draft preparation: all authors; discussion and conclusions: F.S.-A. and F.J.S.-S.; review and editing: F.S.-A. and P.M.-A.

Funding: This research received no external public and/or private funding.

Conflicts of Interest: The authors declare no conflicts of interest.

\section{Appendix A}

Table A1. Target concepts, attributes, and stimuli for IATs.

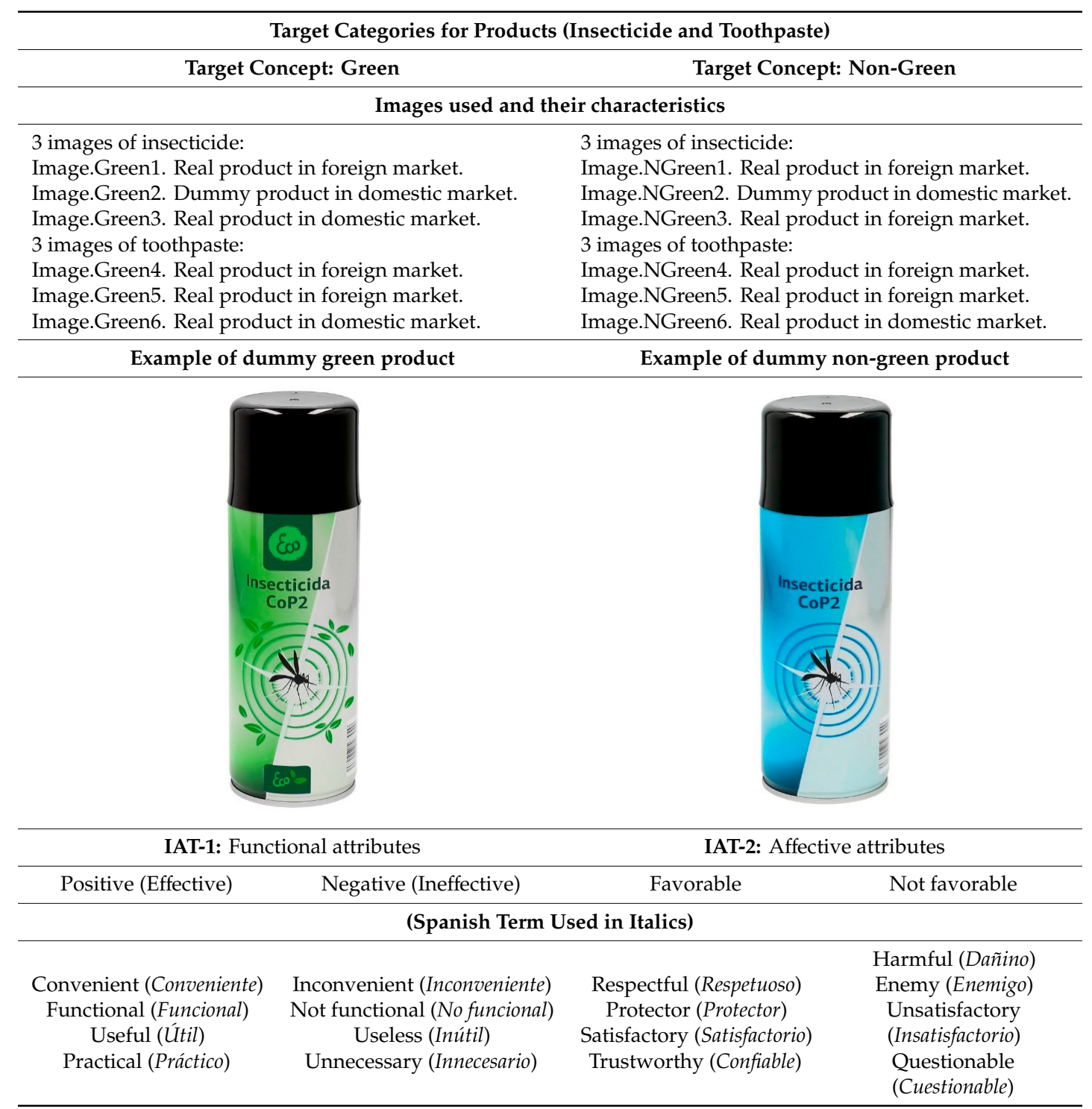

\section{References}

1. Barbarossa, C.; De Pelsmacker, P. Positive and negative antecedents of purchasing eco-friendly products: A comparison between green and non-green consumers. J. Bus. Ethics 2016, 134, 229-247. [CrossRef]

2. Hozik, M. Making the Green by Going Green: Increased Demand for Green Products and the FTC's Role in a Greener Future. Georgetown Environmental Law Review. 1 February 2016. Available online: http://bit.ly/2IWUtb4 (accessed on 18 August 2019).

3. European Commission. Single Market for Green Products Initiative. 2018. Available online: http: //ec.europa.eu/environment/eussd/smgp/index.htm (accessed on 18 August 2019). 
4. Akbar, W.; Hassan, S.; Khurshid, S.; Niaz, M.; Rizwan, M. Antecedents affecting customer's purchase intentions towards green products. J. Sociol. Res. 2014, 5, 273-289. [CrossRef]

5. Joshi, G.Y.; Rahman, Z. Factors affecting green purchase behaviour and future research directions. Int. Strateg. Manag. Rev. 2015, 3, 128-143. [CrossRef]

6. Mohd Suki, N. Green product purchase intention: Impact of green brands, attitude, and knowledge. Br. Food J. 2016, 118, 2893-2910. [CrossRef]

7. Blair, I.V.; Dasgupta, N.; Glaser, J. Implicit attitudes. In APA Handbooks in Psychology. APA Handbook of Personality and Social Psychology, Vol. 1. Attitudes and Social Cognition; Mikulincer, M., Shaver, P.R., Borgida, E., Bargh, J.A., Eds.; American Psychological Association: Washington, DC, USA, 2015; pp. 665-691. [CrossRef]

8. Vantomme, D.; Geuens, M.; De Houwer, J.; De Pelsmacker, P. Implicit attitudes toward green consumer behavior. Psychol. Belg. 2005, 45, 217-239. [CrossRef]

9. Levine, D.S.; Strube, M. Environmental attitudes, knowledge, intentions and behaviors among college students. J. Soc. Psychol. 2012, 152, 308-326. [CrossRef]

10. Pegan, G.; de Luca, P. Can implicit and explicit attitudes predict green product choice under time pressure? An experimental research. J. Manag. World Bus. Res. 2012, 9, 21-36.

11. Matthes, J.; Wonneberger, A. The skeptical green consumer revisited: Testing the relationship between green consumerism and skepticism toward advertising. J. Advert. 2014, 43, 115-127. [CrossRef]

12. Goh, S.K.; Balaji, M.S. Linking green skepticism to green purchase behavior. J. Clean. Prod. 2016, 131, $629-638$. [CrossRef]

13. Mostafa, M.M. Antecedents of Egyptian consumers' green purchase intentions: A hierarchical multivariate regression model. J. Int. Consum. Mark. 2006, 19, 97-126. [CrossRef]

14. Albayrak, T.; Caber, M.; Moutinho, L.; Herstein, R. The influence of skepticism on green purchase behavior. Int. J. Bus. Soc. Sci. 2011, 2, 189-197.

15. Albayrak, T.; Aksoy, Ş.; Caber, M. The effect of environmental concern and scepticism on green purchase behaviour. Mark. Intell. Plan. 2013, 31, 27-39. [CrossRef]

16. Strack, F.; Werth, L.; Deutsch, L. Reflective and impulsive determinants of consumer behavior. J. Consum. Psychol. 2006, 16, 205-216. [CrossRef]

17. Friese, M.; Hofmann, W.; Schmitt, M. When and why do implicit measures predict behaviour? Empirical evidence for the moderating role of opportunity, motivation, and process reliance. Eur. Rev. Soc. Psychol. 2008, 19, 285-338. [CrossRef]

18. Warshaw, P.; Davis, F. Disentangling behavioral intention and behavioral expectation. J. Exp. Soc. Psychol. 1985, 21, 213-228. [CrossRef]

19. Schiffman, L.G.; Kanuk, L.L. Consumer Behavior, 7th ed.; Prentice Hall: Upper Saddle River, NJ, USA, 2007.

20. Bredahl, L.; Søndergaard, H.A.; Grunert, K.G.; Scholderer, J. Trade-Offs in the Formation of Consumer Purchase Intentions with Regard to Complex Genetically Modified Products. Australian Scholarly Publishing. 2004. Available online: http://bit.ly/301qEMt (accessed on 15 May 2019).

21. Kim, A.J.; Ko, E. Do social media marketing activities enhance customer equity? An empirical study of luxury fashion brand. J. Bus. Res. 2012, 65, 1480-1486. [CrossRef]

22. Bagozzi, R.P.; Belanche, D.; Casaló, L.V.; Flavián, C. The role of anticipated emotions in purchase intentions. Psychol. Mark. 2016, 33, 629-645. [CrossRef]

23. Damasio, A.R. The Feeling of What Happens: Body and Emotion in the Making of Consciousness; HarcourtBrace: New York, NY, USA, 1999.

24. Schmitt, B. Experiential Marketing. J. Mark. Manag. 1999, 15, 53-67. [CrossRef]

25. Morwitz, V.G.; Steckel, J.H.; Gupta, A. When do purchase intentions predict sales? Int. J. Forecast. 2007, 23, 347-364. [CrossRef]

26. Morwitz, V. Consumers' purchase intentions and their behavior. Found. Trends ${ }^{\circledR}$ Mark. 2014, 7, $181-230$. [CrossRef]

27. Bagozzi, R.P. The self-regulation of attitudes, intentions and behavior. Soc. Psychol. Q. 1992, 55, $178-204$. [CrossRef]

28. Fabrigar, L.R.; Macdonald, T.K.; Wegener, D.T. The structure of attitudes. In The Handbook of Attitudes; Albarracin, D., Johnson, B., Zanna, M., Eds.; Lawrence Erlbaum Associates: Hillsdale, NJ, USA, 2014; pp. 79-124.

29. Solomon, M.R. Consumer Behaviour. Buying, Having and Being; Prentice Hall: London, UK, 2011. 
30. Wyer, R.S., Jr.; Albarracín, D. Belief formation, organization, and change: Cognitive and motivational influences. In The Handbook of Attitudes; Albarracín, D., Johnson, B., Zanna, M., Eds.; Lawrence Erlbaum Associates: Hillsdale, NJ, USA, 2014; pp. 273-322.

31. Claudy, M. An Empirical Investigation of Consumer Resistance to Green Product Innovation. Ph.D. Thesis, Dublin Institute of Technology, Dublin, Ireland, 2011. [CrossRef]

32. Gervais, M.M.; Fessler, D.M. On the deep structure of social affect: Attitudes, emotions, sentiments, and the case of "contempt". Behav. Brain Sci. 2017, 40, e225. [CrossRef] [PubMed]

33. Rudman, L.A. Sources of implicit attitudes. Curr. Dir. Psychol. Sci. 2004, 13, 79-82. [CrossRef]

34. Wilson, T.D.; Lindsey, S.; Schooler, T.Y. A model of dual attitudes. Psychol. Rev. 2000, 107, 101-126. [CrossRef] [PubMed]

35. Bar-Anan, Y.; Vianello, M. A multi-method multi-trait test of the dual-attitude perspective. J. Exp. Psychol. Gen. 2018, 147, 1264-1272. [CrossRef] [PubMed]

36. Cohen, J.B.; Reed, A. A multiple pathway anchoring and adjustment (MPAA) model of attitude generation and recruitment. J. Consum. Res. 2006, 33, 1-15. [CrossRef]

37. Carruthers, P. Implicit versus explicit attitudes: Differing manifestations of the same representational structures? Rev. Philos. Psychol. 2018, 9, 51-72. [CrossRef]

38. McKenzie, R.M.; Carrie, E. Implicit-explicit attitudinal discrepancy and the investigation of language attitude change in progress. J. Multiling. Multicult. Dev. 2018, 39, 830-844. [CrossRef]

39. Hofmann, W.; Gawronski, B.; Gschwendner, T.; Le, H.; Schmitt, M. A meta-analysis on the correlation between the implicit association test and explicit self-report measures. Pers. Soc. Psychol. Bull. 2005, 31, 1369-1385. [CrossRef]

40. Greenwald, A.G.; Banaji, M.R. Implicit social cognition: Attitudes, self-esteem, and stereotypes. Psychol. Rev. 1995, 102, 4-27. [CrossRef]

41. Bargh, J.A. The four horsemen of automaticity: Awareness, intention, efficiency, and control in social cognition. In Handbook of Social Cognition: Basic Processes and Applications; Wyer, R.S., Jr., Srull, T.K., Eds.; Lawrence Erlbaum Associates, Inc.: Hillsdale, NJ, USA, 1994; pp. 1-40.

42. Conner, T.; Barrett, L.F. Implicit self-attitudes predict spontaneous affect in daily life. Emotion 2005, 5, 476. [CrossRef] [PubMed]

43. Brownstein, M. The Implicit Mind: Cognitive Architecture, the Self, and Ethics; Oxford University Press: Oxford, UK, 2018.

44. Madva, A.; Brownstein, M. Stereotypes, prejudice, and the taxonomy of the implicit social mind1. Noûs 2018, 52, 611-644. [CrossRef]

45. Devine, P.G. Stereotypes and prejudice: Their automatic and controlled components. J. Personal. Soc. Psychol. 1989, 56, 5-18. [CrossRef]

46. Amodio, D.M. Social Cognition 2.0: An interactive memory systems account. Trends Cogn. Sci. 2018, 23, 21-33. [CrossRef] [PubMed]

47. Trendel, O.; Werle, C.O. Distinguishing the affective and cognitive bases of implicit attitudes to improve prediction of food choices. Appetite 2015, 104, 33-43. [CrossRef]

48. Obermiller, C.; Spangenberg, E.R.; MacLachlan, D.L. Ad skepticism: The consequences of disbelief. J. Advert. 2005, 34, 7-17. [CrossRef]

49. Schutijser, D. Cynicism as a way of life: From the classical cynic to a new cynicism. Akropolis J. Hell. Stud. 2017, 1, 33-54. [CrossRef]

50. Turner, J.H.; Valentine, S.R. Cynicism as a fundamental dimension of moral decision-making: A scale development. J. Bus. Ethics 2001, 34, 123-136. [CrossRef]

51. Abraham, R. Organizational cynicism: Bases and consequences. Genet. Soc. Gen. Psychol. Monogr. 2000, 126, 269-292. [PubMed]

52. Chylinski, M.; Chu, A. Consumer cynicism: Antecedents and consequences. Eur. J. Mark. 2010, 44, $796-837$. [CrossRef]

53. Helm, A.E. Cynical Consumers: Dangerous Enemies, Loyal Friends. Ph.D. Thesis, University of Missouri-Columbia, Columbia, MO, USA, 2006.

54. Helm, A.E.; Moulard, J.G.; Richins, M. Consumer cynicism: Developing a scale to measure underlying attitudes influencing marketplace shaping and withdrawal behaviours. Int. J. Consum. Stud. 2015, 39, 515-524. [CrossRef] 
55. Pollay, R.W. The distorted mirror: Reflections on the unintended consequences of advertising. J. Mark. 1986, 50, 18-36. [CrossRef]

56. Odou, P.; De Pechpeyrou, P. Consumer cynicism: From resistance to anti-consumption in a disenchanted world? Eur. J. Mark. 2011, 45, 1799-1808. [CrossRef]

57. Mohr, L.A.; Eroglu, D.; Ellen, P.S. The development and testing of a measure of skepticism toward environmental claims in marketers' communications. J. Consum. Aff. 1998, 32, 30-55. [CrossRef]

58. Ryu, H.; Jun, S. Asymmetric negative influence of cynicism and skepticism: A study of preventative communication. Int. J. Advert. 2019, 38, 1-26. [CrossRef]

59. Chang, C.T.; Cheng, Z.H. Tugging on heartstrings: Shopping orientation, mindset, and consumer responses to cause-related marketing. J. Bus. Ethics 2014, 127, 337-350. [CrossRef]

60. Berndsen, M.; Van der Pligt, J. Ambivalence towards meat. Appetite 2004, 42, 71-78. [CrossRef]

61. Thøgersen, J.; de Barcellos, M.D.; Perin, M.G.; Zhou, Y. Consumer buying motives and attitudes towards organic food in two emerging markets: China and Brazil. Int. Mark. Rev. 2015, 32, 389-413. [CrossRef]

62. Moser, A.K. Thinking green, buying green? Drivers of pro-environmental purchasing behavior. J. Consum. Mark. 2015, 32,167-175. [CrossRef]

63. Eagly, A.H.; Chaiken, S. The Psychology of Attitudes; Harcourt Brace Jovanovich College Publishers: Fort Worth, TX, USA, 1993.

64. Chen, M.F. Consumer attitudes and purchase intentions in relation to organic foods in Taiwan: Moderating effects of food-related personality traits. Food Qual. Prefer. 2007, 18, 1008-1021. [CrossRef]

65. Honkanen, P.; Verplanken, B.; Olsen, S.O. Ethical values and motives driving organic food choice. J. Consum. Behav. 2006, 5, 420-430. [CrossRef]

66. Demirtas, B. Assessment of the impacts of the consumers' awareness of organic food on consumption behavior. Food Sci. Technol. 2018. [CrossRef]

67. D'Souza, C.; Taghian, M.; Lamb, P.; Peretiatkos, R. Green products and corporate strategy: An empirical investigation. Soc. Bus. Rev. 2006, 1, 144-157. [CrossRef]

68. Wee, C.S.; Ariff, M.S.B.M.; Zakuan, N.; Tajudin, M.N.M.; Ismail, K.; Ishak, N. Consumers perception, purchase intention and actual purchase behavior of organic food products. Rev. Integr. Bus. Econ. Res. 2014, 3, 378-397.

69. Lee, Y.K. A comparative study of green purchase intention between Korean and Chinese consumers: The moderating role of collectivism. Sustainability 2017, 9, 1930. [CrossRef]

70. Kim, S.; Pysarchik, D.T. Predicting purchase intentions for uni-national and bi-national products. Int. J. Retail Distrib. Manag. 2000, 28, 280-291. [CrossRef]

71. Chan, R.Y.K. Determinants of Chinese consumers' green purchase behavior. Psychol. Mark. 2001, 18, $389-413$. [CrossRef]

72. Greenwald, A.G.; McGhee, D.E.; Schwartz, J.K.L. Measuring individual differences in implicit cognition: The implicit association test. J. Personal. Soc. Psychol. 1998, 74, 1464-1480. [CrossRef]

73. Brunel, F.F.; Tietje, B.C.; Greenwald, A.G. Is the implicit association test a valid and valuable measure of implicit consumer social cognition? J. Consum. Psychol. 2004, 14, 385-404. [CrossRef]

74. De Houwer, J.; Geldof, T.; De Bruycker, E. The implicit association test as a general measure of similarity. Can. J. Exp. Psychol. 2005, 59, 228-239. [CrossRef]

75. Spence, A.; Townsend, E. Implicit attitudes towards genetically modified (GM) foods: A comparison of context-free and context-dependent evaluations. Appetite 2006, 46, 67-74. [CrossRef] [PubMed]

76. Richetin, J.; Mattavelli, S.; Perugini, M. Increasing implicit and explicit attitudes toward an organic food brand by referencing to oneself. J. Econ. Psychol. 2016, 55, 96-108. [CrossRef]

77. Sarabia-Andreu, F.; Sarabia-Sánchez, F.J. Do implicit and explicit attitudes explain organic wine purchase intention? An attitudinal segmentation approach. Int. J. Wine Bus. Res. 2018, 30, 463-480. [CrossRef]

78. Schnabel, K.; Asendorpf, J.B.; Greenwald, A.G. Assessment of individual differences in implicit cognition: A review of IAT measures. Eur. J. Psychol. Assess. 2008, 24, 210-217. [CrossRef]

79. Gattol, V.; Sääksjärvi, M.; Carbon, C.C. Extending the implicit association test (IAT): Assessing consumer attitudes based on multi-dimensional implicit associations. PLoS ONE 2011, 6, e15849. [CrossRef]

80. Greenwald, A.G.; Nosek, B.A.; Banaji, M.R. Understanding and using the Implicit Association Test: I. An improved scoring algorithm. J. Personal. Soc. Psychol. 2003, 85, 197-216. [CrossRef]

81. Storage, D. IAT Scoring Made Easy: An Automated R Script to Analyze Implicit Association Test Output. RPubs. 2016. Available online: https://rpubs.com/dstorage/IAT (accessed on 31 March 2019). 
82. Maher, J.M.; Markey, J.C.; Ebert-May, D. The other half of the story: Effect size analysis in quantitative research. CBE Life Sci. Educ. 2013, 12, 345-351. [CrossRef]

83. Gil, J.M.; Gracia, A.; Sánchez, M. Market segmentation and willingness to pay for organic products in Spain. Int. Food Agribus. Manag. Rev. 2000, 3, 207-226. [CrossRef]

84. Khoiriyah, S.; Toro, M.J.S. Attitude toward green product, willingness to pay and intention to purchase. Int. J. Bus. Soc. 2018, 19 (Suppl. S4), 620-628.

85. Swalwell, G.C. Change My Mind: The Moderating Impact of Scepticism and Cynicism on Perceived Source Credibility and Informational Claims in Social Advertising. Ph.D. Thesis, Queensland University of Technology, Brisbane, QLD, Australia, 2018.

86. Joshi, G.Y.; Sheorey, P.A.; Gandhi, A.V. Analyzing the barriers to purchase intentions of energy efficient appliances from consumer perspective. Benchmark. Int. J. 2019, 26, 1565-1580. [CrossRef]

87. Brislin, R.W. Wording and translation in research instruments. In Field Methods in Cross-Cultural Research; Lonner, W., Berry, J., Eds.; Sage: Newbury Park, CA, USA, 1984; pp. 137-164.

88. Behling, O.; Law, K.S. Translating Questionnaires and Other Research Instruments; SAGE Research Methods: Thousand Oaks, CA, USA, 2000.

89. Mason, W.; Allon, S.; Ozturk, P. Open Source Web-Bases IAT Computer Software. 2013. Available online: https://github.com/winteram/IAT (accessed on 3 March 2016).

90. Bentler, P.M. EQS 6 Structural Equations Program Manual; Multivariate Software: Encino, CA, USA, 2005.

91. Fornell, C.; Larcker, D.F. Evaluating structural equation models with unobservable variables and measurement error. J. Mark. Res. 1981, 18, 39-50. [CrossRef]

92. Anderson, J.; Gerbing, D. Structural equation modeling in practice: A review and recommended two step approach. Psychol. Bull. 1988, 103, 411-423. [CrossRef]

93. Hair, J.F., Jr.; Black, W.C.; Babin, B.J.; Anderson, R.E. Multivariate Data Analysis, 7th ed.; Pearson Education: New York, NY, USA, 2009.

94. Jain, V. 3D model of attitude. Int. J. Adv. Res. Manag. Soc. Sci. 2014, 3, 1-12.

95. Maniatis, P. Investigating factors influencing consumer decision-making while choosing green products. J. Clean. Prod. 2016, 132, 215-228. [CrossRef]

96. Wei, C.F.; Chiang, C.T.; Kou, T.C.; Lee, B.C. Toward sustainable livelihoods: Investigating the drivers of purchase behavior for green products. Bus. Strategy Environ. 2017, 26, 626-639. [CrossRef]

97. Yu, S.; Lee, J. The effects of consumers' perceived values on intention to purchase upcycled products. Sustainability 2019, 11, 1034. [CrossRef]

98. Nosek, B.A.; Greenwald, A.G.; Banaji, M.R. Understanding and using the implicit association test: II. Method variables and construct validity. Personal. Soc. Psychol. Bull. 2005, 31, 166-180. [CrossRef]

99. Ecological 2018. Spanish Organic Sector 2018. Available online: http://www.ecological.bio/en/sectorbio2018 (accessed on 13 August 2019). 